
\title{
25 Research Square \\ Experimental Investigation of the Effect of EDM Parameters and Dielectric Type on the Surface Integrity and Topography
}

Hasan Rahimi

Azad University

Soroush Masoudi ( $\sim$ smasoudi86@gmail.com )

Young Researcher and Elite Club, https://orcid.org/0000-0002-4487-2121

Majid Tolouei-Rad

Edith Cowan University

\section{Research Article}

Keywords: EDM, Surface Topography, Recast layer, Micro Crack, HAZ, Microhardness

Posted Date: June 29th, 2021

DOl: https://doi.org/10.21203/rs.3.rs-596298/v1

License: (c) (1) This work is licensed under a Creative Commons Attribution 4.0 International License. Read Full License

Version of Record: A version of this preprint was published at The International Journal of Advanced Manufacturing Technology on September 22nd, 2021. See the published version at https://doi.org/10.1007/s00170-021-08040-z. 


\section{Abstract}

The electrical discharge machining (EDM) process is mostly used in conditions that complex and intricate shapes need to be machined on very hard metals. However, the process leaves behind some undesirable properties such as high surface roughness, rough topography, high residual tensile stresses, micro-cracks, heat-affected zone (HAZ) and recast layer. This paper investigates the effects of different output parameters on the properties listed above. The input parameters studied include current, pulse-on time, and the type of dielectric; and the material being machined is AISI 1045 steel. Results show that the deionized water improved the output variables in EDM. The use of deionized water as the dielectric, not only improved the machined surfaces' topography but also lowered the micro-cracks and HAZ thickness. The experiments also show how the pulse-on and current time affect the outcome of EDM machining of AISI 1045 steel.

\section{Introduction}

Electrical discharge machining (EDM) is one of the advanced machining processes widely used in machining of complex shapes and parts made of hard alloys and materials. In this process, an electrical discharge between the workpiece and electrode (tool) that are submerged in a dielectric media occurs and causes the removal of molten metal from the surface of workpiece. By repeating this phenomenon, machining operations is gradually carried out and eventually, a depression having the inverse shape of the tool is created on the workpiece [1]. In Electrical discharge machining, the electrical sparks are used for machining of materials that are electrically conductive. Whereas the distance between the tool and the workpiece is very small, the dielectric will be ionized and pulse current can flow between electrodes separated by a small $(\mu \mathrm{m})$ gap that lead the occurring of discharging and creation of plasma channel. The temperatures of spark is very high (around $8500-12,500^{\circ} \mathrm{C}$ ) that are sufficient for melting and vaporize the metals [2-3].

Parts machined by this process are generally subjected to severe conditions of temperature, stress, and hostile environments. Failure analyses of dynamic components and service histories indicated that severe failures, produced by corrosion cracking, creep, fatigue, generally start near parts surface and their beginning depend on the quality of surface. Therefore, great attention must be paid to surface integrity of parts processed by EDM [4-5]. Surface integrity involves macro and microstructure, surface finish, microhardness variations, residual stresses and heat-affected zone. Burning/overheating, deposits of debris, surface irregularities, macro and micro- cracks, micro defects such as inclusions and laps, metallurgical alterations like phase transformations, tensile residual stresses heat-affected layers, are the dominant problems in EDM. These problems are mainly attributed to thermal physical loads during machining [6-7].

In addition to surface integrity, surface topography plays a significant role in the evaluation of the machined surfaces. In the past, surface textures were measured by using devices such as contact stylus profiler method. The method has several restrictions, which include a high contact force, a large stylus 
radius, and relatively low magnification that leads to damage of sample surface. In addition, this device might misrepresent the topography of surface due to the limited size of the stylus tip. In the last decades, advanced methods such as 3D optical microscope and atomic force microscopy (AFM) have been developed to achieve a 3D image of different surfaces like surface of machined parts. These techniques eliminate the drawbacks of the stylus profiler method and present a 3D image of measured surfaces [89].

Researchers have tried to optimize EDM processes to achieve favorable surface integrity and topography [10-12]. Obratański et al. [13] investigated surface integrity of Ti 6Al 4V in high power EDM machining.

The results showed that the excessive gradients of pressure and temperature in EDM result in the growth and formation of cracks. Mahdieh [14] evaluated the effect of EDM variables on the thickness of heataffected zone (HAZ). Based on the published results, in both cases of tool polarity (negative and positive), an increase in duty cycle and pulse-on time, lead to a rise in the depth of heat-affected zone. Also with increasing pulse-on time, hardness rate declined in the layers near the machined surfaces. Paul et al. [15] evaluated white layer thickness, surface roughness, surface crack density in conventional and powder mixed EDM. The results showed that the level of surface irregularities has been improved when copper powder mixed to the dielectric in comparison with conventional EDM (no-powder). Based on their results, an increase in the duration of pulse-on has improved surface roughness but the high level of surface micro-cracks is created, while the increased duration of pulse-on time and current has resulted in the creation of thicker recast layer. Shabgard et al. [16] performed experimental and FEM investigations of the heat-affected zone and white layer thickness in EDM machining. Both experimental and numerical results proved that increasing the pulse-on time resulted in a higher surface roughness, higher depth of $H A Z$, and greater white layer thickness due to the lower efficiency of plasma flushing in the higher pulseon time. However, an increase in the current leads to a slight reduction of depth of HAZ and the white layer. Khosrozadeh and Shabgard [17] investigated the effects of powder-mixed dielectric EDM (PMEDM) and ultrasonic-assisted EDM (USEDM), on surface integrity parameters such as heat-altered metal zone, surface roughness, residual stress and micro cracks. According to their results, the residual stress level was partially lower in the ultrasonic-assisted process compared with PMEDM and conventional EDM process. In addition, heat-altered metal layer was reduced in PM-USEDM compared EDM process. Gu [18] investigated the effect of current intensity, pulse duration on surface roughness, surface morphology, and micro-crack in EDM machining. Based on the results, by using the low pulse energy appropriate surface integrity can be achieved and avoid excessive machined surface damage. The results also indicated that the AFM method could be applied to achieve a 3-dimensional picture with a micrometer scale and to investigate the micro-cracks' depth on EDM surface.

From the literature it is evident that much research is performed in the EDM of metallic materials, however, there is room for investigation on the effect of EDM variables on surface integrity and the topography of AISI 1045 steel. In addition, the effect of dielectric fluid on surface topography is not intelligibly studied in the literature and generally, the change of surface roughness has been reported. In the present research, EDM experiments were carried out to study the surface characteristics at different machining conditions, including the surface topography, micro-cracks, heat-affected zone and recast 
layers. Micro-cracks and HAZ are evaluated with an SEM microscope and surface topography is analyzed by a 3D optical microscope.

\section{Experiments}

Experiments were conducted on an EDM machine (Js Edm Model). The EDM machine has 4-axis with the movement accuracy of $0.5 \mu \mathrm{m}$. The machine is worked with Isopulse-type system so that the pulses time are equal which makes identical energy intensity in all sparks.

The pulse-on time and current are the most important input variables in EDM that change in their level have a significant influence on surface integrity and other output parameters. Therefore, in the experiments, these two parameters have been considered as input parameters. Also, dielectric fluid is one of the most influential parameters in EDM that affecting machining outputs and characteristics. Hence, in order to evaluate the effect of dielectric type, experiments were performed using two different fluids, namely deionized water and kerosene. The resistivity of deionized water could be easily reduced by the absorption of $\mathrm{CO}_{2}$ from the air and should be maintained carefully. Accordingly, fresh deionized water is continuously supplied to the discharge zone by using a nozzle from a deionized water tank. Accordingly, machining experiments were designed based on the full factorial method with 3 levels of current intensity, 3 levels of pulse-on time and 2 types of dielectric as input parameters. Table 1 represents machining input variables and their levels used in the experiments.

Table 1

EDM input parameters and their levels

\begin{tabular}{|lllll|}
\hline Machining Parameters & level & & & Unit \\
\hline & A & B & C & \\
\hline Current $(I)$ & 3 & 6 & 9 & A \\
pulse-on time $\left(\mathrm{T}_{\text {on }}\right)$ & 50 & 100 & 150 & $\mu \mathrm{s}$ \\
\hline dielectric type $\left(\mathrm{P}_{\mathrm{T}}\right)$ & Kerosene & Deionized Water & - & \\
\hline
\end{tabular}

The experiments were performed on the round samples AISI 1045 steel with a size of $15 \mathrm{~mm}$ in diameter and $10 \mathrm{~mm}$ in length. The surface of samples before EDM machining were ground using a grinding machine to reach the roughness of $0.4 \mu \mathrm{m} \mathrm{Ra}$. Machining was taking place at a distance of $20 \mathrm{~cm}$ below the surface of the dielectric. In all experiments voltage was set on $40 \mathrm{~V}$, the pulse-off time setting on $50 \mu \mathrm{s}$ and the material of the electrode was copper with negative polarity and machining time adjusted on 20 minute. In order to measure the roughness of the workpieces, a surface roughness measuring instrument (T550-Hommel model) was utilized. A Bruker-GTK 3D optical microscope was used to evaluate the surface topography of the machined parts. The main advantage of using optical methods is the measurement time and the measurement uncertainty is $\Delta x=0.75$ to $0.6 \mu \mathrm{m}$ on the basis of Bruker-GTK's microscope catalog. The topography was evaluated in a scanning area of approximately 80 by $80 \mathrm{~mm}$ in 
the center of the surfaces machined. All parts were also investigated using the scanning electron microscopy (SEM) for detecting surface micro cracks and measure the heat-affected zone. The microhardness changes of workpiece subsurface after EDM were measured to the depth of $55 \mu \mathrm{m}$ from the surface using a Vickers microhardness tester machine (KOOPA-MH4 model). For measurement of microhardness, a load of $100 \mathrm{~g}$ with a dwell time of $10 \mathrm{~s}$ was applied so that the device created a micrometric square pyramid at the desired location, and then hardness value (in Vickers) was calculated automatically using Haresh software.

\section{Results And Discussion}

\subsection{Surface topography and roughness}

The surface topography as an output of EDM is a function of machining conditions and process variables like discharging voltage, current, pulse-on time, and dielectric type. Upon completion of machining operations and measuring surface roughness, the influences of different input variables on the topography of machined surfaces have been investigated using a three-dimensional optical microscope. Figures 1(a), (b) and (c) show 3D topography images of the machined surfaces when using two types of dielectric fluids, deionized water and kerosene, each at the currents of 9, 6 and 3A, respectively. In all experiments represented in Fig. 1, pulse-on time was fixed and set on $150 \mu$ s.

Based on the results it is observed that surface topography is a function of released energy in the discharge area since a rougher surface with more cavity and craters is produced when a higher current is used. Conversely, at lower peak current a finer surface is produced as in this condition a small quantity of molten material is removed from the surface due to the lower discharge energy. With current increases the discharge energy rises and this ultimately increases the intensity of the plasma channel. As plasma channel increases the discharge power also increases and results in a higher material removal rate from the surface that ultimately leads to producing a rougher surface topography.

As seen in Fig. 1, the surface cavities and holes produced on the surface of the machined samples in kerosene are deeper and possess a rougher topography in comparison with the samples machined in deionized water. This indicates that in deionized water the change of pressure over the discharge area is not as substantial as that in kerosene. When kerosene is used as the dielectric, the expansion of the generated bubbles created in discharging zone will be hampered because of the high viscosity and inertia of kerosene, while in deionized water this phenomenon is limited due to dielectric's extremely low viscosity and density [19]. Accordingly, the pressure over the discharge zone could experience a much more fluctuation and faster expansion speeds of the bubbles because of the constriction effect of kerosene. The higher pressure over the discharge zone in kerosene increases the impulsive force acting on the machined surface due to the contraction and expansion of the discharge generated bubbles; and this ultimately leads to higher material removal efficiency and a rougher surface with more cavities, craters and irregularly shaped appendages in comparison with the parts machined in deionized water. In addition, kerosene is a kind of hydrocarbon oil which decomposes at higher temperatures in the 
discharging zone and creates carbon debris during electrical discharge machining. These carbon scraps are stored in machined surface and restrain the stable and efficient discharging process, preventing generation of a smooth surface [20-21]. Whereas, in machining with deionized water, due to the lack of carbonization, the machining environment is stable and clean which results in producing parts with a smoother surface topography. Unlike distilled or pure water, in deionized water the probity of oxidation is much lower, and this enhances machining efficiency. Therefore, it can be clearly seen that the topography of the machined surfaces produced in the deionized water as dielectric is advantageous compared with those produced in the kerosene dielectric.

Figure 2 shows 3D images of the topography of the surface produced in deionized water at the current of $3 \mathrm{~A}$ and pulse-on times of 150 (a), 100(b) and $50 \mu \mathrm{s}$ (c), respectively. The 3D images presented in this figure clearly indicate that the pulse-on-time affects the topography of the surfaces machined; however, the change of current has a greater effect. In short-timed pulses the pressure over the discharge zone is very high and this may prevent an efficient molten material removal. As pulse time increases the pressure of discharge zone is dramatically reduced because of the faster expansion of the bubble generated in discharge point. In addition, in a higher pulse-on time, i.e. $150 \mu \mathrm{s}$, the heat conduction increases and the discharge plasma channel also increases as a result. In this case, the material removal rate increases, and more molten material is removed from each puddle on the workpiece surface, leading to a rougher surface topography. Moreover, longer pulse-on time results in more frequent cracking of the dielectric and higher rate of material expulsion leading to the generation of a rougher surface topography [22].

Figures 3(a) and 3(b) show the influence of pulse duration and current on the average surface roughness $(\mathrm{Ra})$, respectively. Similar to surface topography results, the Ra value is increased when current and pulse time increase. Also, a higher value of Ra was measured in the parts machined in kerosene. Based on the results, the maximum surface roughness of $3.56 \mu \mathrm{m}$ was reached when machining at the current of $9 \mathrm{~A}$, a pulse-on time of $150 \mu \mathrm{s}$, and when using kerosene as dielectric. Accordingly, the minimum roughness of $2.82 \mu \mathrm{m}$ was measured with a current of $3 \mathrm{~A}$, a pulse-on time of $50 \mu \mathrm{s}$, and when using the deionized water dielectric. From the above it can be concluded that for polish machining when the smooth surface in needed, a lower current and pulse-on time should be selected with using deionized water instead of kerosene. These results are in accordance with the surface topography results obtained and analyzed as explained before. However, extracting the 3D image of machined surface reveals an excellent and comprehensive sense of machined surface morphology as parameters such as Ra and Rz are quantitative and two surfaces with totally different topographies could have the same Ra or Rz values. Therefore, use of advanced methods such as 3D optical microscope and atomic force microscopy (AFM) is beneficial for precise evaluation of the 3D morphology of machined surfaces.

\subsection{Surface micro cracks}

One of the most important factors influencing the integrity of machined is surface micro-crack, and directly affecting the fatigue resistance and performance of the parts. The micro-cracks on the machined surfaces are formed as a result of residual stresses generated in the subsurface. Residual stresses during 
electrical discharge machining are generated because of reasons such as non-uniformity in thermal stresses, metallurgical phase transformation and local crystal plastic deformation [23-25]. However, in EDM the scale of plastic deformation and its effects on the residual stresses is very small as there is no contact between the electrode and part and local crystal plastic deformation in EDM is resulted because of very high thermal stress generated during the process.

Figure 4 presents the effect of current intensity on the surface micro-cracks created on the machined surface with deionized water at the pulse-on time of $150 \mu \mathrm{m}$ and the current of 9 (a), 6 (b) and 3A (c), respectively. As seen in Fig. 4 there is no trace of surface micro-cracks for the current of $3 \mathrm{~A}$, while relatively wide and large micro-cracks are present on the surface when a higher currents of 6 or $9 \mathrm{~A}$ is used. With increasing current in EDM, the size and number of micro-cracks increase rapidly. In machined parts with higher currents, the length of micro-cracks is increased, and the span width of the surface cracks is larger. In general, with increasing current in EDM machining, the density and strength of the plasma channel created between the two electrodes increases which enlarges the spark power and discharge energy. Due to higher discharge energy, the higher thermal gradient is created on the machined surface, which develops more micro cracks. As mentioned before, there is no trace of micro-crack at low current of 3 A while surface micro cracks are evident when higher currents of 6 and 9 are used. This is mainly due to a higher thermal gradient, which results in the generation of tensile stresses exceeding the maximum tensile strength of the material. According to the results, an increase in current intensity leads to the expansion of surface micro-cracks, which endangers the integrity of the surface being machined. Therefore, it is recommended that low currents are used for machining of sensitive parts that will be subjected to cyclic loads and fatigue to prevent or lower the possibility of formation of micro-cracks on the surface.

Figures 5(a), (b) and (c) show 3D images of the surface micro-cracks in two types of dielectric fluid, i.e. deionized water and kerosene, at the pulse-on times of 50,100 and $150 \mu \mathrm{s}$, respectively. In all experiments represented in this image, the current was fixed at $6 \mathrm{~A}$. As seen in the Fig. 5, the intensity and width of micro-cracks is relatively increased at higher pulse times and when using kerosene. The micro-cracks follow closed loops with pitting arrangements and continue to propagate when other discharges take place at the near regions.

As seen in Fig. 5, the longer pulse-on-times, i.e. 100 and $150 \mu$ s, to some extent more and larger microcracks are generated. However, the rate of increase in surface micro-cracks because of higher pulse-on time is much less than that of using higher currents in EDM. In higher pulse-on time, energy input in the discharge zone will be increased, which increases the supplied heat energy and thermal gradient on the machined surface; and this consequently increases the micro-cracks density.

The possibility cracking also increases when kerosene is used as the dielectric liquid especially at high pulse durations. In the machined parts with kerosene relatively more crack propagation along the grain boundary occurred in comparison with deionized water. As mentioned earlier, due to lower viscosity and density of the deionized water compared with kerosene, less pressure over the discharge zone is 
generated and impulsive force acting on the machined surface is also lower. Accordingly, less spark intensity and lower thermal gradient are exposed on the machined surface, which results in lower probability of micro-cracks creation in machining with deionized water. Another cause for the creation of more cracks on the machined surface in kerosene is the difference in thermal conductivities of two kinds of dielectrics that change the cooling rate in the discharge zone. The high cooling rate of deionized water efficiently dissipates the heat from the melted material and restricts the formation of micro-cracks. Moreover, in EDM machining with kerosene as the dielectric, due to carbonization, carbon derbies adhere to the electrode surface and this ultimately leads to creating carbide on the workpiece surface [26]. This condition causes unstable machining on the discharge zone that is accompanied with higher impulsive force, resulting in the higher tendency of crack propagation in machining with kerosene.

\subsection{Recast layer, HAZ and microhardness}

Generally, in electrical discharge machining the dielectric fluid is inefficient in completely flushing out the entire melted material and debris. As a result, a part of melted material is deposited onto the discharged surface that is called recast layer. Recast layer and heat-affected zone are part of an altered material zone that is created on discharged surface. One of major output variables in EDM machining is the heataffected zone (HAZ), especially in sensitive parts, which are exposed to fatigue loading. HAZ is an area of discharged subsurface where the base material was not melted; however, the subsurface mechanical properties and microstructure were dramatically changed due to exposure to high-temperature gradient in machining. These regions of machined subsurface are brittle, very hard and because of the nonhomogeneities of metallurgical phases within it, are very prone to develop micro-cracks.

Figure 6 Effect of current and dielectric type on the recast layer thickness at the pulse-on times of 50 (a), 100 (b) and $150 \mu \mathrm{s}(\mathrm{c})$

In all experiments presented in Fig. 7, the pulse-on-time was fixed at $150 \mu \mathrm{s}$. These images clearly demonstrate the effect of different EDM conditions on the thickness of recast layer. These images are taken at 1200x magnification. Figure 7 shows that the thickness of the recast layer on the machined subsurface varies from 7 to $18 \mu \mathrm{m}$ and increases with increasing current and using kerosene as the dielectric. However, the influence of current on recast layer thickness is greater than that of the dielectric type.

In addition, in order to characterize the mechanical properties of machined subsurface, microhardness test has been performed using a Vickers microhardness tester. The hardness profiles of machined samples under different machining conditions are presented in Fig. 8. These microhardness profiles correspond to cross-sections of the machined samples shown in Fig. 7. The maximum hardness values of machined subsurface were measured $415 \mathrm{HV}$, whereas microhardness of the un-affected base material was about $170 \mathrm{HV}$. It can be observed in Fig. 8 that these hardness profiles can be divided into three sections. The first section correspond to the recast layer where the formation of carbon is resulted when the hardness of recast layer is between 416 and $397 \mathrm{HV}$ and that is significantly higher than the hardness of base material. Beneath the recast layer, the HAZ area is created in the machining subsurface, which its 
hardness is lower than that of the recast layer but is higher than base material. Clearly the subsurface mechanical properties of HAZ and its hardness were dramatically changed due to exposure to hightemperature gradient in EDM machining. As can be seen in Fig. 8, HAZ layers have different slopes of hardness variation in different machining conditions and the hardness value in HAZ zone decreased in the higher depth form the recast layer. This indicates that changes in mechanical properties in higher depths were lower due to a lower temperature gradient. These results also support the fact that microhardness of the recast layer and HAZ can be approximately 2-3 times larger than that of the unaffected base metal [27-28]. As shown in Fig. 7, there is a direct relationship between the heataffected zone and recast layer thickness as the thickness of recast layer and HAZ was increased with increasing the current density.

From the above discussion, it is perceived that when for electrical discharge machining of AISI 1045 steel at the current of $3 \mathrm{~A}$, the lowest thickness of recast layer and HAZ thicknesses are achieved; and it becomes even lower when deionized water is used as the dielectric. On the contrary, the highest thickness of recast layer and HAZ thicknesses are resulted at the current of $9 \mathrm{~A}$ and when kerosene is used as the dielectric. The relation between discharge energy and as pulse-on time as well as current is directional. An increase in peak current leads to increased discharge energy that in turn creates a thicker recast layer and consequently produces a larger HAZ. In fact, in the higher values of current and pulse duration, discharge energy is enlarged, and this results in a higher material removal rate (MRR). The higher MRR results in an increase in material debris in the discharge zone that smooths the way for secondary sparking. Therefore, higher discharge energy and secondary sparking lead to an increase in the recast layer and HAZ thicknesses. On the other hand, an increase in pulse-on time causes incomplete flushing of material derbies. Partial flushing of debris due to higher pulse-on time results in higher heat accumulation and thermal gradient on electrically discharge machined subsurface, leading to an increase in the recast layer thickness.

In all machining conditions with deionized water, the depth of recast layer and HAZ were reduced. This reduction is more evident in the higher currents (i.e. 6 and 9 A). Based on Figs. 7 (c) and 8 (c), there was little difference between the recast layer and HAZ thickness in the parts machined with a current of $3 \mathrm{~A}$ as the measured recast layer in EDM with kerosene and deionized water was 8 and $7 \mu \mathrm{m}$, respectively. However, as the current was increased the difference became more evident. For instance, at the current of 9 A the recast layer thickness was 15 and $18 \mu \mathrm{m}$ with kerosene and deionized water dielectrics, respectively (Figs. 7 (a) and 8(a)). Because of the higher thermal conductivity of water than kerosene and faster cooling in the presence of deionized water, the length of plasma channel in deionized water is more than kerosene. In addition, the rate of igniting breakdown and plasma channel formation is faster in water dielectric fluid. In this condition, discharge energy is dispersed to a larger zone and there is less accumulated energy prior the breakdown point, leading to the reduction of recast layer and HAZ thicknesses in EDM machining with deionized water as the dielectric fluid [29]. In addition, effective cooling of material during EDM with deionized water prevents the formation of thick recast layer leading to a lower HAZ thickness. 


\section{Conclusion}

This paper studied the effects of three output parameters in EDM machining of AISI 1045 steel including surface topography and surface roughness, micro-cracks, microhardness, HAZ and recast layer. The EDM experiments were performed for different values of current (3, 6 and 9 A), pulse-on time (50, 100 and 150 $\mu \mathrm{s})$, and types of dielectric (i.e. deionized water and kerosene) to provide a proper understanding of the relationship between input and output parameters. The following conclusions can be drawn from the results of this study:

- Experimental results revealed that among the three input parameters considered; the pulse current has the maximum effect on output parameters. The current had the greatest influence on surface topography, Ra, surface micro-cracks and HAZ and recast layer thickness. It can be observed, from the results that by increasing the current all three output parameters increased. A similar trend was also observed for the pulse-on time as for a higher pulse duration the discharge energy is also increased. Therefore, a lower current and pulse duration values should be used where smooth topography with minimum surface damage is required.

Based on the achieved results, EDM machining with deionized water as the dielectric is superior to kerosene as it results in achieving a better surface topography, lower surface micro-cracks, as well as lower recast layer and heat-affected zone thickness. Results also indicated that there is a direct relationship between the recast layer and heat-affected zone based on the microhardness profile of machined subsurface. These results clarify that the type of dielectric significantly changes the discharging process and directly affects all output parameters. The higher efficiency of deionized water was due to its lower viscosity and density, which results in less pressure over the discharge zone and impulsive force. Also, the higher cooling rate of deionized water efficiently dissipates the heat from the melted material and restricts the formation of micro-cracks and heat-affected zone. Although kerosenebased dielectric is the most used in commercial EDM machines, the results of this research indicated that deionized water is the most preferred dielectric in EDM. This is since, unlike kerosene, it does not generate carbon debris during discharging. Therefore, the use of deionized water also assists in providing a safer and healthier work environment when working with EDM. As a conclusion, for producing sensitive parts where higher surfaces finish and especially lower surface damage such as micro-cracks and HAZ is required, the use of deionized water as the dielectric is highly recommended.

\section{Declarations}

\section{- Funding}

This research received no specific grant from any funding agency in the public, commercial, or not-forprofit sectors

\section{- Conflicts of interest/Competing interests}


On behalf of all authors, the corresponding author states that there is no conflict of interest.

\section{- Availability of data and material}

Not applicable

- Code availability (software application or custom code)

Not applicable

\section{- Authors' contributions}

Experiments performed by Mr. Hasan Rahimi and he provided the conception and design of the study. Mr. Soroush Masoudi supervised development of work and performed analysis and interpretation of data, wrote manuscript and acted as corresponding author. Mr. Majid Rad helped in data interpretation and manuscript evaluation.

\section{- Acknowledgments}

The authors would like to thank Dr. Ghanbari form University of Kashan for providing the 3D optical microscope in order to surface topography measurement.

\section{References}

1. HuuPhan, Nguyen T, Muthuramalingam NN, Vu, Nguyen Quoc T (2020) "Influence of micro size titanium powder-mixed dielectric medium on surface quality measures in EDM process". Int J Adv Manuf Technol 109(3):797-807. DOI:10.1007/s00170-020-05698-9

2. Maher I, Sarhan AAD, Hamdi M (2014) Review of Improvements in Wire Electrode Properties for Longer Working Time and Utilization in Wire EDM Machining. Int J Adv Manuf Technol 76(14):329-351. DOI:10.1007/s00170-014-6243-3

3. Nayak D, Sahu SN, Mula S. Metallurgical approach towards explaining optimized EDM process parameters for better surface integrity of AISI D2 tool steel. Trans. Indian Inst. Met, 201770(5), 11831191

4. DOI:10.1007/s12666-016-0910-z

5. Dhakar K, Chaudhary K, Dvivedi A, Bembalge O (2019) An Environment-Friendly and Sustainable Machining Method: Near-Dry EDM. Mater Manuf Process 34(12):1307-1315.

DOI:10.1080/10426914.2019.1643471

6. Camposeco-Negrete C (2019) Prediction and Optimization of Machining Time and Surface Roughness of AISI 01 Tool Steel in Wire-Cut EDM Using Robust Design and Desirability Approach. Int J Adv Manuf Technol 103(5-8):2411-2422. DOl:10.1007/s00170-019-03720-3

7. Al-Amin M, Abdul Rani AM, Abdu Aliyu AA, Abdul Razak MA, Hastuty S, Bryant MG (2020) Powder Mixed-EDM for Potential Biomedical Applications: A Critical Review. Mater Manuf Process 
35(16):1789-1811. DOI:10.1080/10426914.2020.1779939

8. Liu Y, Chang H, Zhang W, Ma F, Sha Z, Zhang SA (2018) Simulation Study of Debris Removal Process in Ultrasonic Vibration Assisted Electrical Discharge Machining (EDM) of Deep Holes.

Micromachines 9(8):378. DOI:10.3390/mi9080378

9. Mahajan A, Sidhu SS (2017) Surface Modification of Metallic Biomaterials for Enhanced

Functionality: A Review. Mater Technol 33(2):93-105. DOI:10.1080/10667857.2017.1377971

10. Nair S, Dutta A, R N, Giridharan A (2019) Investigation on EDM Machining of Ti6Al4V with Negative Polarity Brass Electrode. Mater Manuf Process 34(16):1824-1831.

DOI:10.1080/10426914.2019.1675891

11. Aich, U.; Banerjee, S. Characterizing Topography of EDM Generated Surface by Time Series and Autocorrelation Function. Tribol Int. 2017, 111, 73-90. DOI:10.1016/j.triboint.2017.02.016.

12. \&\#8204

13. Shankar P, Jain VK, Sundararajan T, ANALYSIS OF SPARK, PROFILES DURING EDM PROCESS (1997) Mach Sci Technol 1(2):195-217. DOI:10.1080/10940349708945647

14. Raj S, Rahul; Sinha HR, Shivani; Das S, Guha S, Aazim; Banik D, Routara BC Optimization of Surface Topography of Electro- Discharge Machined Super Alloy Inconel 825: Using TOPSIS Integrated with Taguchi Philosophy. Mater.Today Proc. 2020, 24, 218-224. DOI:10.1016/j.matpr.2020.04.270

15. Karmiris-Obratański P, Zagórski K, Cieślik J, Papazoglou EL, Markopoulos A (2020) Surface Topography of Ti 6Al 4V ELI after High Power EDM. Procedia Manuf 47:788-794. DOI:10.1016/j.promfg.2020.04.242

16. Mahdieh MS (2019) Recast Layer and Heat-Affected Zone Structure of Ultra-Fined Grained LowCarbon Steel Machined by Electrical Discharge Machining. P I Mech Eng. B-J Eng 234(5):933-944. DOI:10.1177/0954405419889202

17. Paul BK, Sahu SK, Jadam T, Datta S, Dhupal D, Mahapatra SS Effects of Addition of Copper Powder in the Dielectric Media (EDM Oil) on Electro-Discharge Machining Performance of Inconel 718 Super Alloys. Mater. Today Proc. 2018, 5 (9), 17618-17626. DOI:10.1016/j.matpr.2018.06.080

18. Shabgard M, Oliaei SNB, Seyedzavvar M, Najadebrahimi A (2011) Experimental Investigation and 3D Finite Element Prediction of the White Layer Thickness, Heat Affected Zone, and Surface Roughness in EDM Process. J Mech Sci Technol 25(12):3173-3183. DOI:10.1007/s12206-011-0905-y

19. Khosrozadeh B, Shabgard M (2017) Effects of Hybrid Electrical Discharge Machining Processes on Surface Integrity and Residual Stresses of Ti-6Al-4V Titanium Alloy. Int J Adv Manuf Technol 93(58):1999-2011. DOI:10.1007/s00170-017-0601-X

20. Guu YH (2005) AFM Surface Imaging of AISI D2 Tool Steel Machined by the EDM Process. Appl Surf Sci 242(3-4):245-250. DOI:10.1016/j.apsusc.2004.08.028

21. Heidari S, Afsari A, Ranaei MA (2020) Increasing Wear Resistance of Copper Electrode in Electrical Discharge Machining by Using Ultra-Fine-Grained Structure. Trans Indian Inst Met 73(11):29012910. DOI:10.1007/s12666-020-02091-8 
22. Singh NK, Pandey PM, Singh KK, Sharma MK (2016) Steps towards green manufacturing through EDM process: a review. Cogent Eng 3(1):1272662. DOI:10.1080/23311916.2016.1272662

23. Zhang Y, Liu Y, Shen Y, Ji R, Li Z, Zheng C (2014) Investigation on the influence of the dielectrics on the material removal characteristics of EDM. J Mater Process Technol 214(5):1052-1061. DOI:10.1016/j.jmatprotec.2013.12.012

24. Ramasawmy H, Blunt L (2004) Effect of EDM process parameters on 3D surface topography. J Mater Process Technol 148(2):155-164. DOI:10.1016/S0924-0136(03)00652-6

25. Chen Z, Moverare J, Peng RL, Johansson S (2016) Surface integrity and fatigue performance of Inconel 718 in wire electrical discharge machining. Procedia CIRP 45:307-310.

DOI:10.1016/j.procir.2016.02.053

26. Liu JF, Guo YB, Butler TM, Weaver ML (2016) Crystallography, compositions, and properties of white layer by wire electrical discharge machining of nitinol shape memory alloy. Mater Des 109:1-9. DOI:10.1016/j.matdes.2016.07.063

27. Masoudi S, Mirabdolahi M, Dayyani M, Jafarian F, Vafadar A, Dorali MR (2018) Development of an Intelligent Model to Optimize Heat-Affected Zone, Kerf, and Roughness in 309 Stainless Steel Plasma Cutting by Using Experimental Results. Mater Manuf Process 34(3):345-356.

DOI:10.1080/10426914.2018.1532579

28. Chen SL, Yan BH, Huang FY (1999) Influence of kerosene and distilled water as dielectrics on the electric discharge machining characteristics of Ti-6A1-4V. J Mater Process Technol 87(1-3):107111. DOI:10.1016/S0924-0136(98)00340-9

29. Yildiz Y, Sundaram MM, Rajurkar KP, Altintas A (2015) Correlation of Surface Roughness and Recast Layer Thickness in Electrical Discharge Machining. P I Mech Eng E-J Pro 231(3):414-424. DOI:10.1177/0954408915600949

30. Zhang Y, Liu Y, Ji R, Cai B (2011) Study of the recast layer of a surface machined by sinking electrical discharge machining using water-in-oil emulsion as dielectric. Appl Surf Sci 257(14):5989-5997. DOI:10.1016/j.apsusc.2011.01.083

31. Klocke F, Schneider S, Ehle L, Meyer H, Hensgen L, Klink A Investigations on surface integrity of heat treated 42CrMo4 (AISI 4140) processed by sinking EDM. Procedia CIRP, 201642, 580-585. DOI:10.1016/j.procir.2016.02.263

\section{Figures}


(a). $I=9 A, T_{\text {on }}=150 \mu \mathrm{S}$

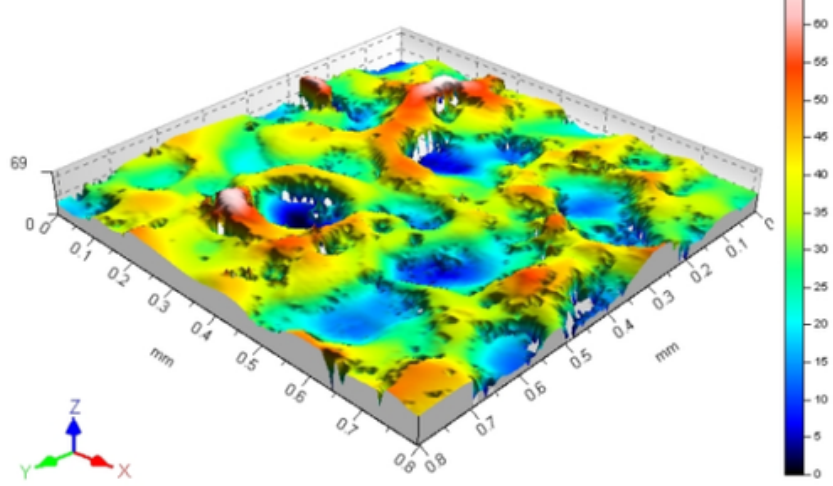

Deionized Water

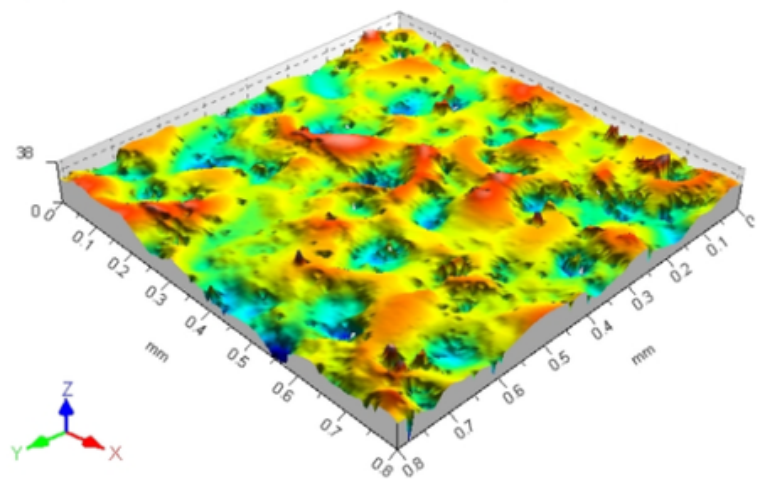

Deionized Water

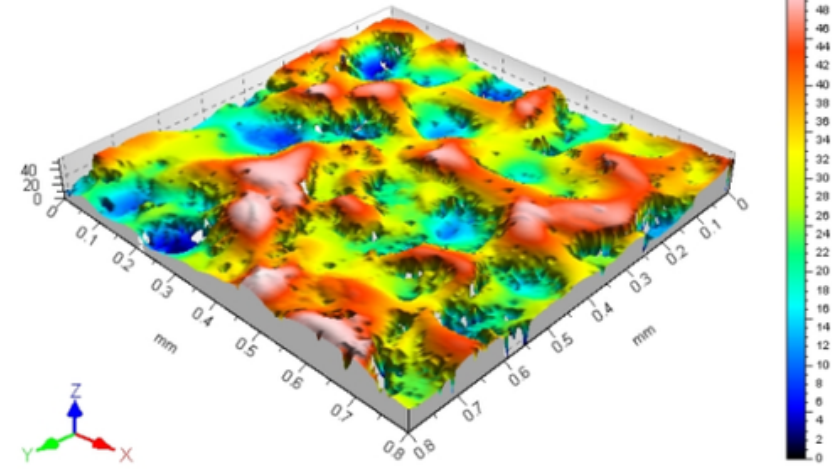

Kerosene

(b). $\mathrm{I}=6 \mathrm{~A}, \mathrm{~T}_{\mathrm{on}}=150 \mu \mathrm{s}$

(c). $\mathrm{I}=3 \mathrm{~A}, \mathrm{~T}_{\mathrm{on}}=150 \mu \mathrm{s}$

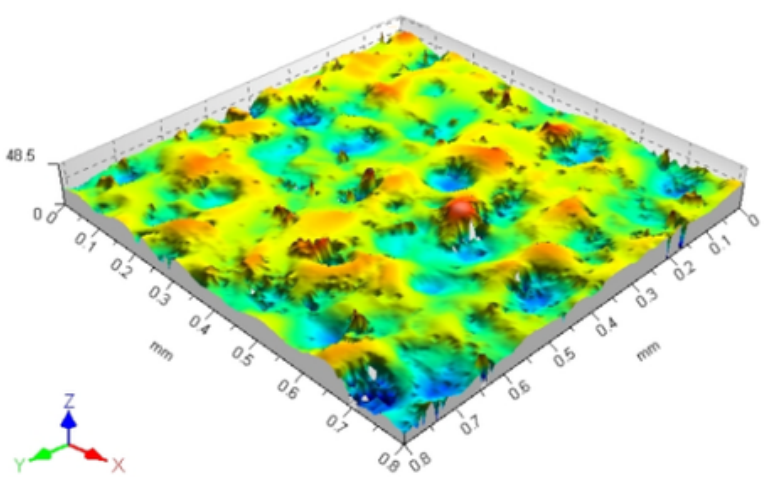

Deionized Water

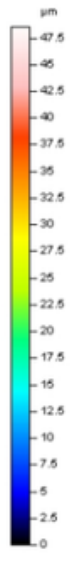

rax

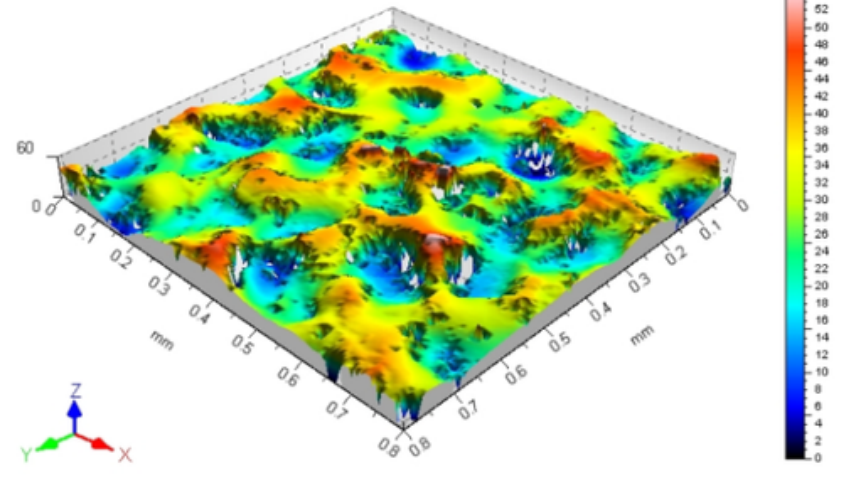

Kerosene

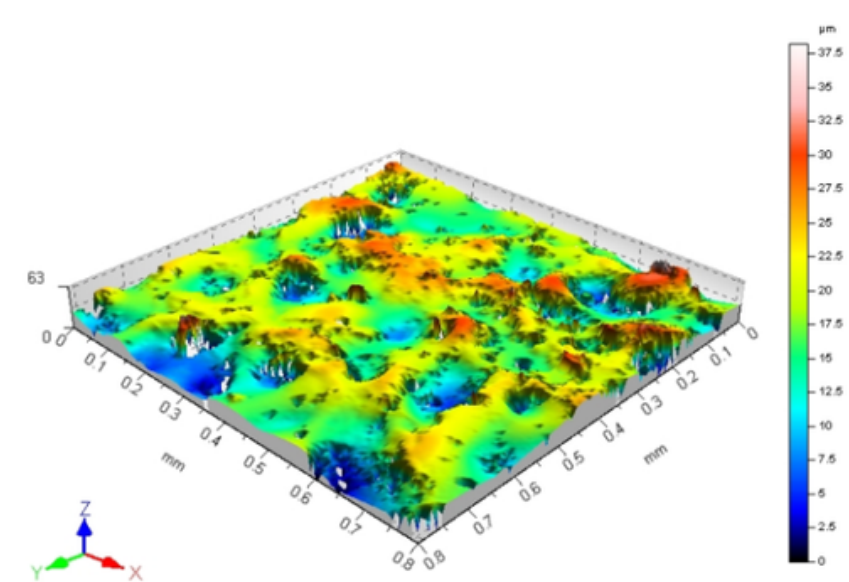

Kerosene

Figure 1

3D images of the topography of surfaces for a pulse-on time of $150 \mu \mathrm{s}$ and using two types of dielectric at the currents of (a) 9A, (b) 6A, and (c) 3A. 
(a). $\mathrm{I}=3 \mathrm{~A}, \mathrm{~T}_{\text {on }}=150 \mu \mathrm{s}$

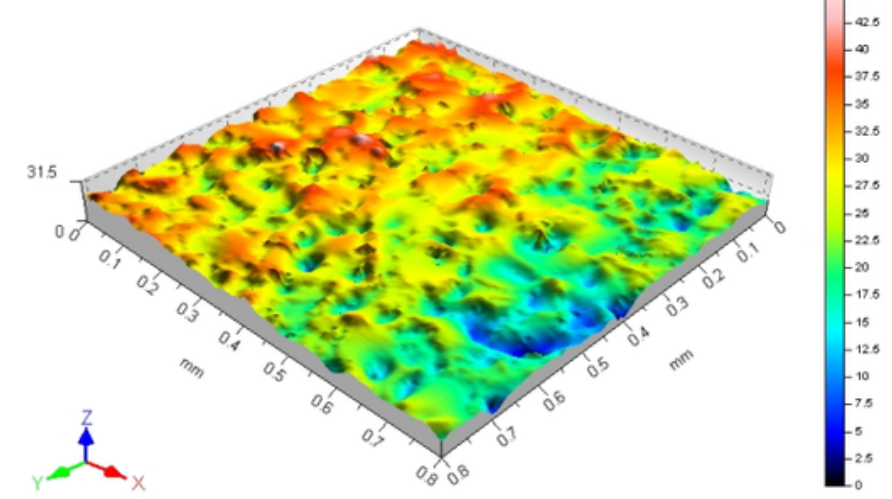

(b). I= $3 \mathrm{~A}, \mathrm{~T}_{\text {on }}=100 \mu \mathrm{s}$

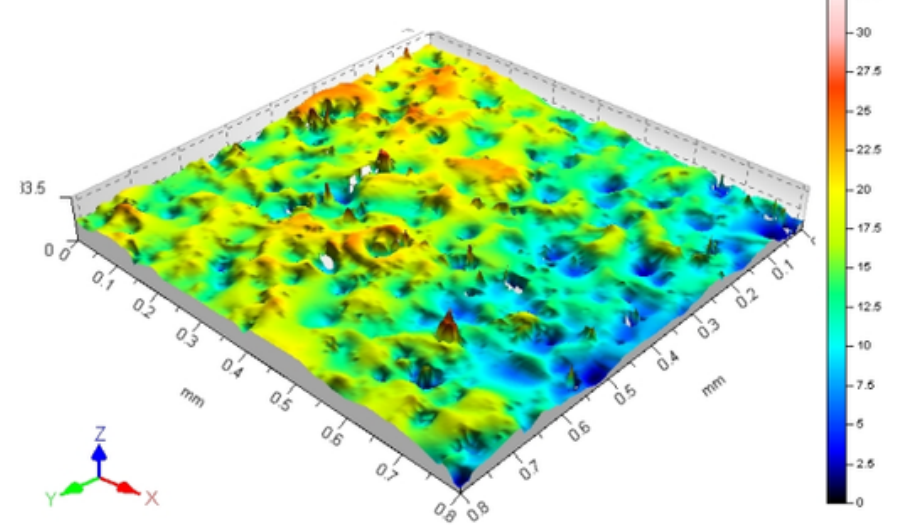

(c). I $=3 \mathrm{~A}, \mathrm{~T}_{\text {on }}=\mathbf{5 0} \mu \mathrm{s}$

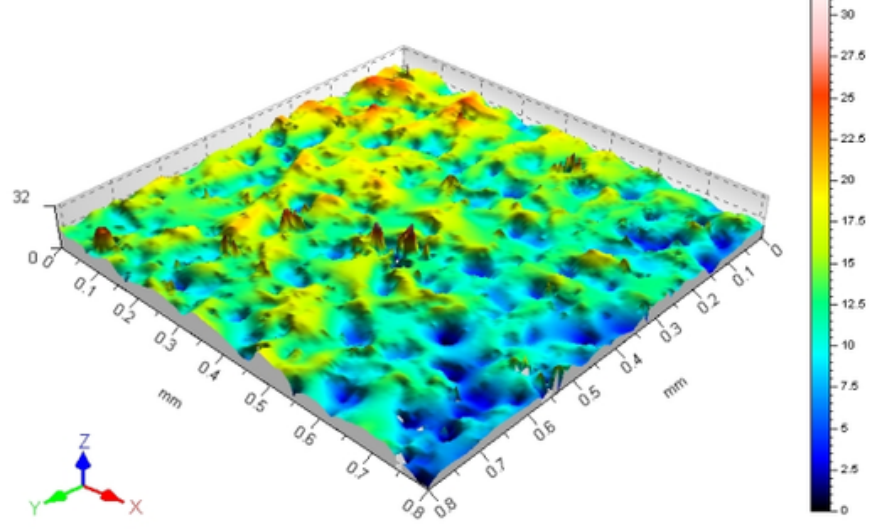

\section{Deionized Water}

\section{Figure 2}

3D images of the topography of surfaces in deionized water dielectric usnig a current of $3 \mathrm{~A}$ and pulse-on times of (a) $150 \mu \mathrm{s},(\mathrm{b}) 100 \mu \mathrm{s}$, and (c) $50 \mu \mathrm{s}$. 

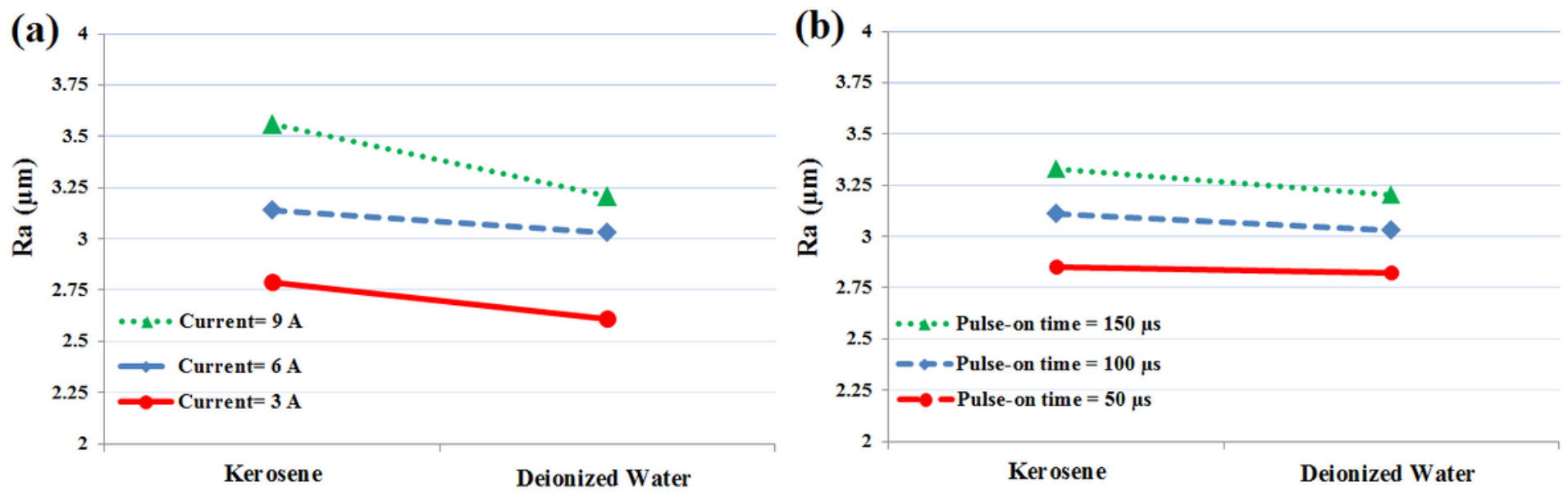

\section{Figure 3}

Ra values at (a) different currents with a fixed pulse-on time of $150 \mu \mathrm{s}$, (b) different pulse-on times with a fixed current of $3 \mathrm{~A}$ 
(a). $\mathrm{I}=9 \mathrm{~A}, \mathrm{~T}_{\text {on }}=150 \mu \mathrm{s}$

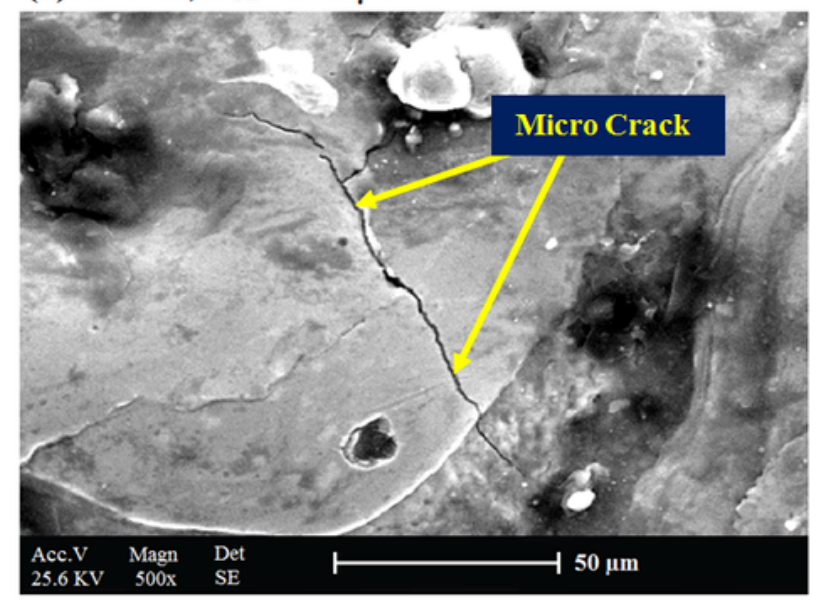

(b). $\mathrm{I}=6 \mathrm{~A}, \mathrm{~T}_{\text {on }}=150 \mu \mathrm{s}$

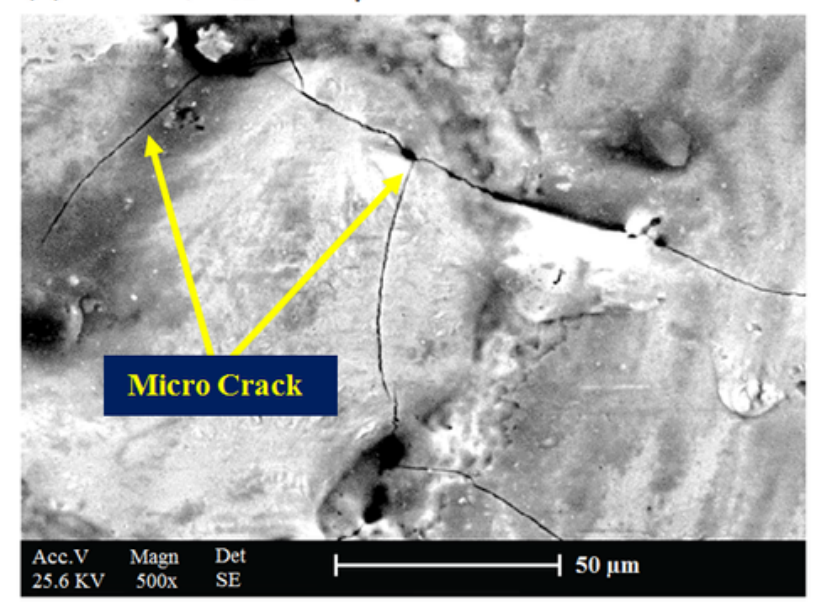

(c). I $=3 \mathrm{~A}, \mathrm{~T}_{\text {on }}=150 \mu \mathrm{s}$

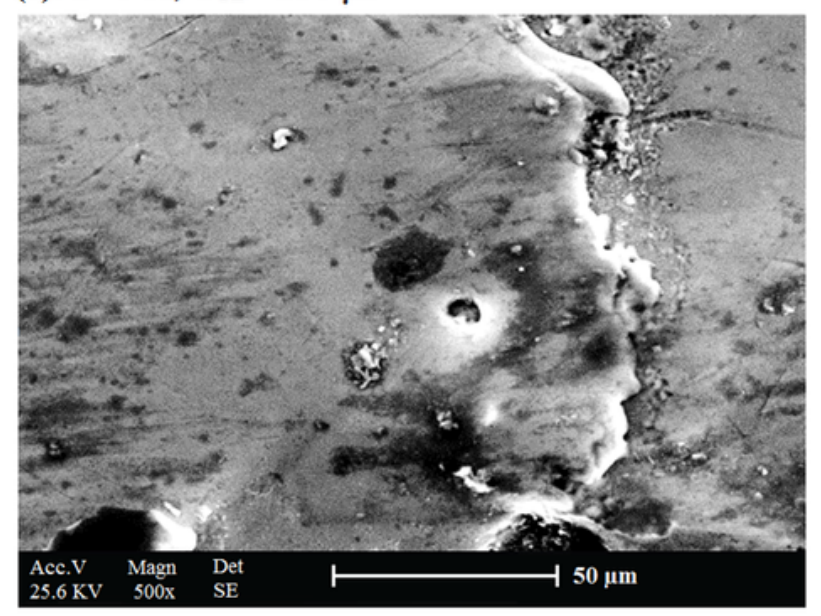

Deionized Water

Figure 4

Surface micro-cracks created on the machined surface with deionized water at the pulse-on time of 150 $\mu$ s and the currents of 9 (a), 6 (b) and $3 A$ (c) 
(a). $I=6 \mathrm{~A}, \mathrm{~T}_{\text {on }}=150 \mu \mathrm{s}$

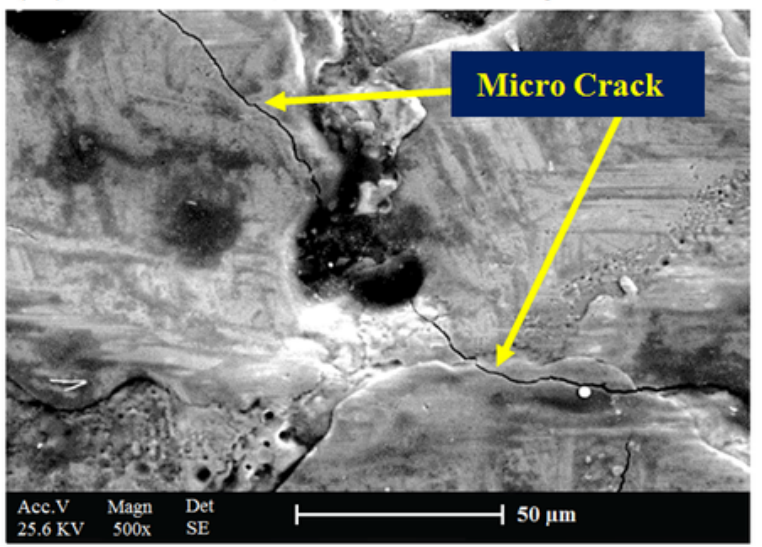

Deionized Water

(b). $I=6 \mathrm{~A}, T_{\text {on }}=100 \mu \mathrm{s}$

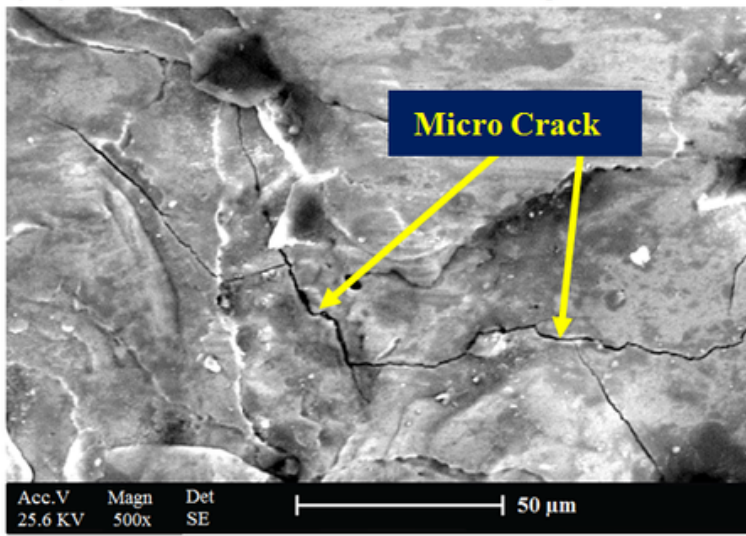

Deionized Water

(c). $I=6 \mathrm{~A}, T_{\text {on }}=50 \mu \mathrm{s}$

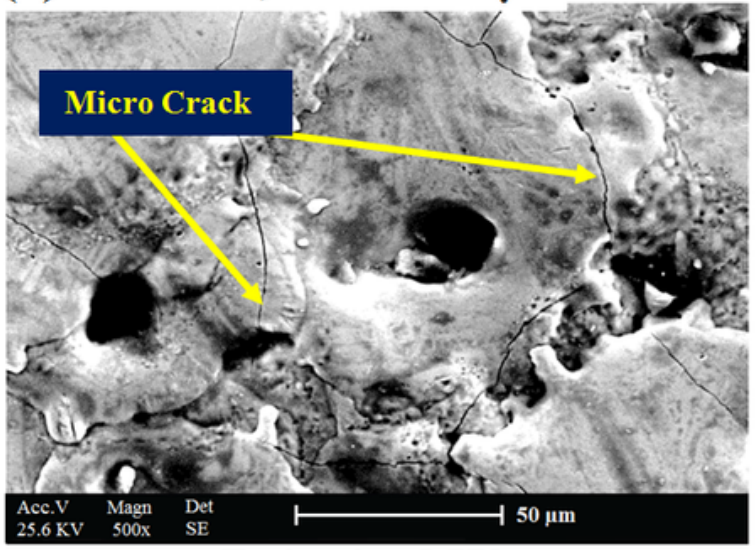

Deionized Water

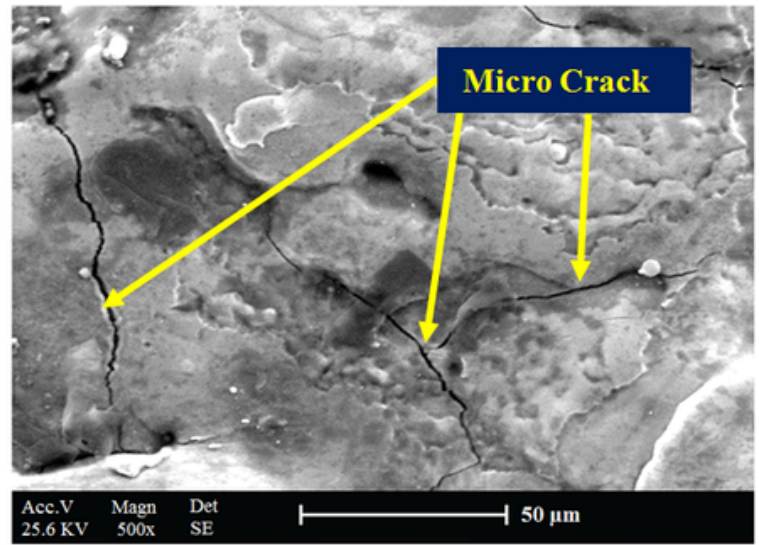

Kerosene

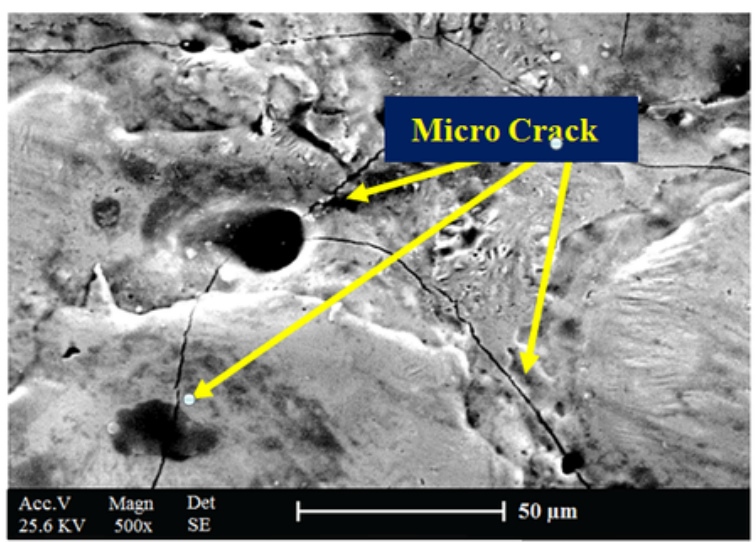

Kerosene

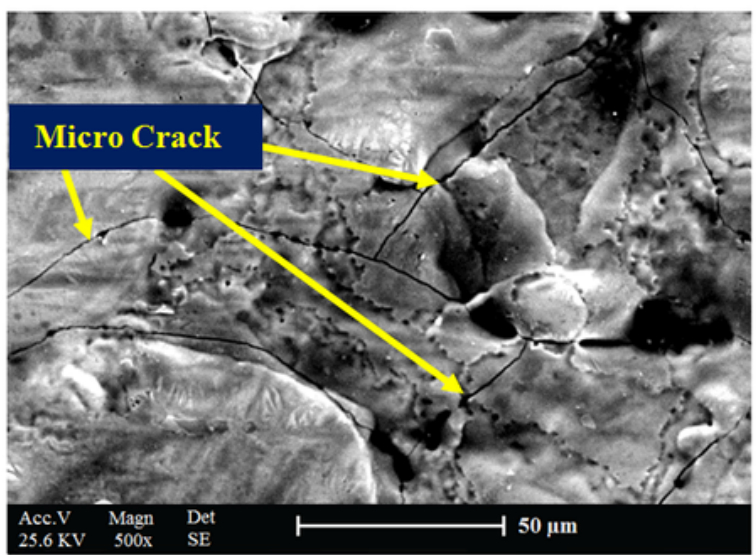

Kerosene

Figure 5

Surface micro-cracks created on the machined surface at the current of $6 \mathrm{~A}$ and the pulse-on times of (a)150, (b) 100, and (c) $50 \mu s$ using two type of dielectric fluid 

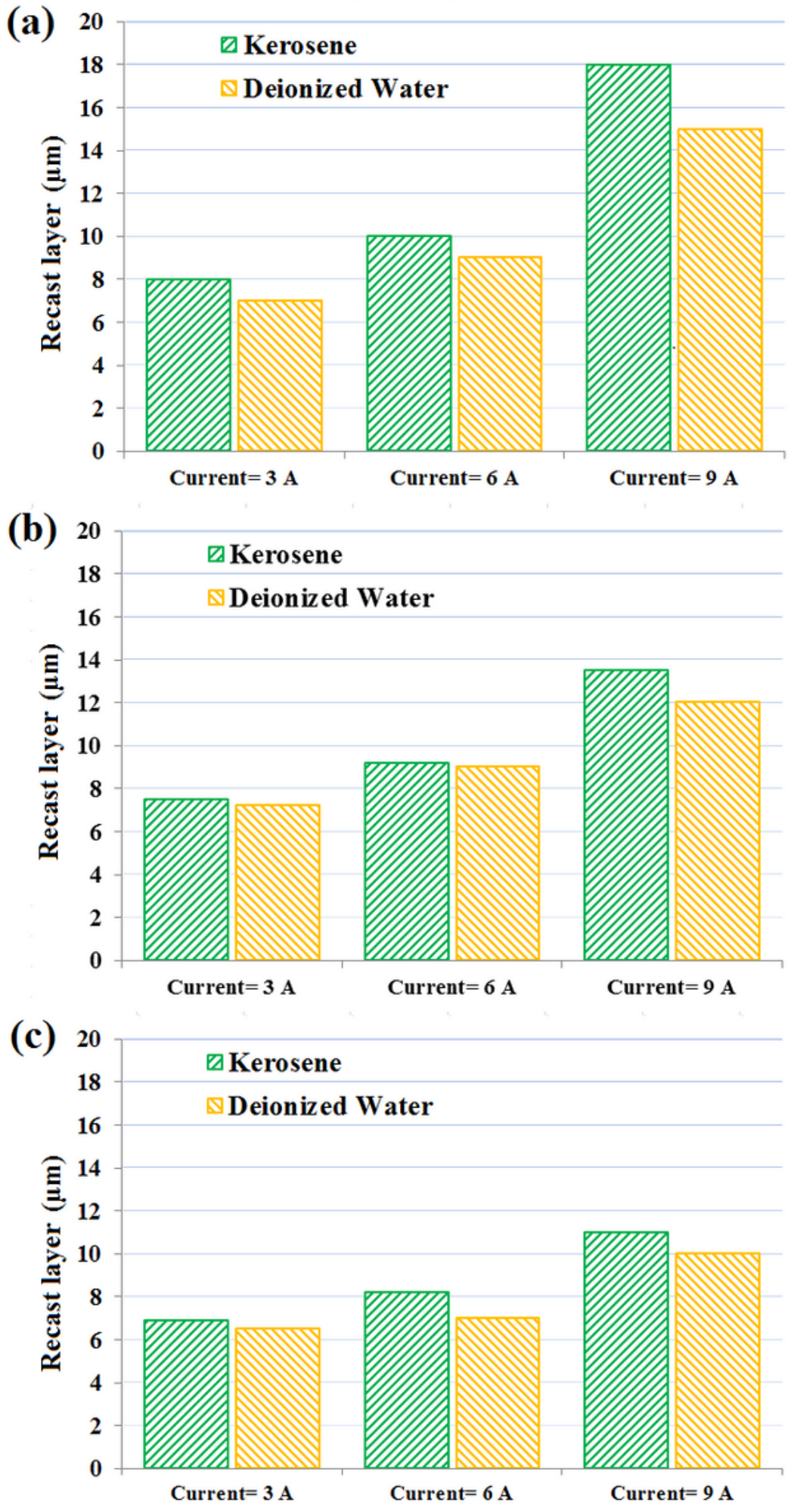

Figure 6

Effect of current and dielectric type on the recast layer thickness at the pulse-on times of 50 (a), 100 (b) and $150 \mu \mathrm{s}(\mathrm{c})$ 
(a). I $=9 \mathrm{~A}, \mathrm{~T}_{\text {on }}=150 \mu \mathrm{S}$

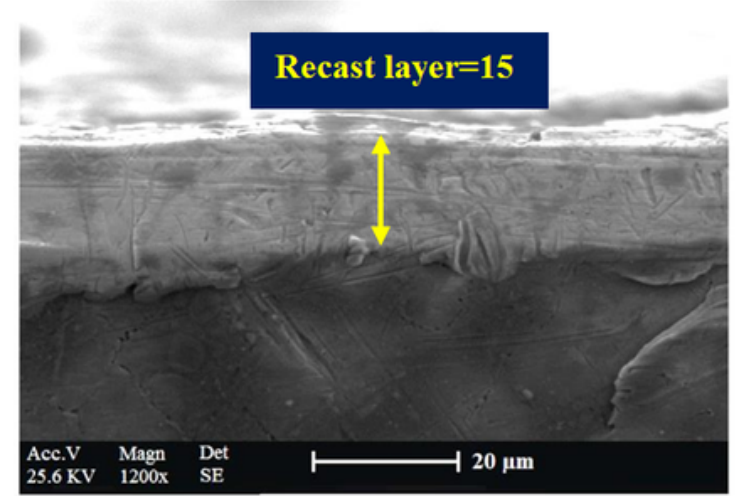

Deionized Water

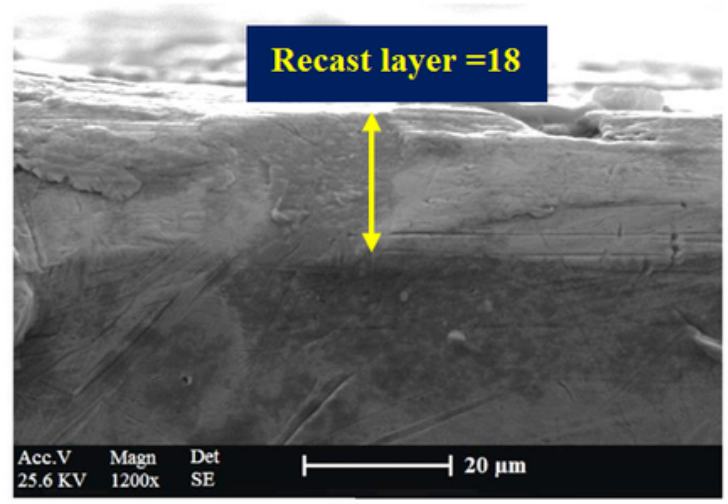

Kerosene

(b). $I=6 \mathrm{~A}, \mathrm{~T}_{\text {on }}=150 \mu \mathrm{s}$

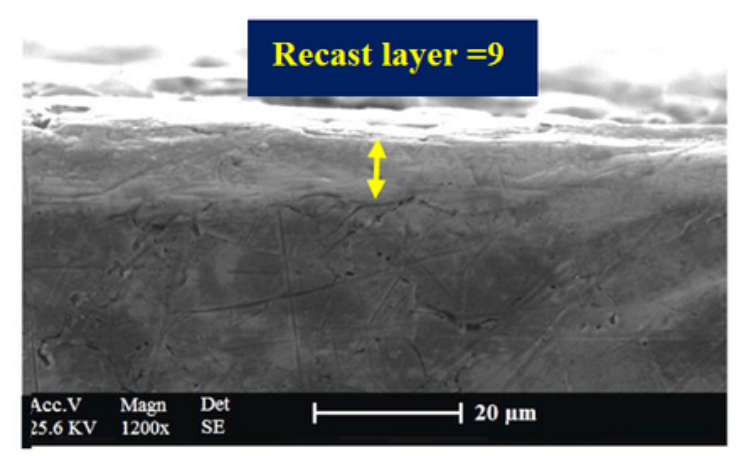

Deionized Water

(c). I= $3 \mathrm{~A}, \mathrm{~T}_{\text {on }}=150 \mu \mathrm{s}$

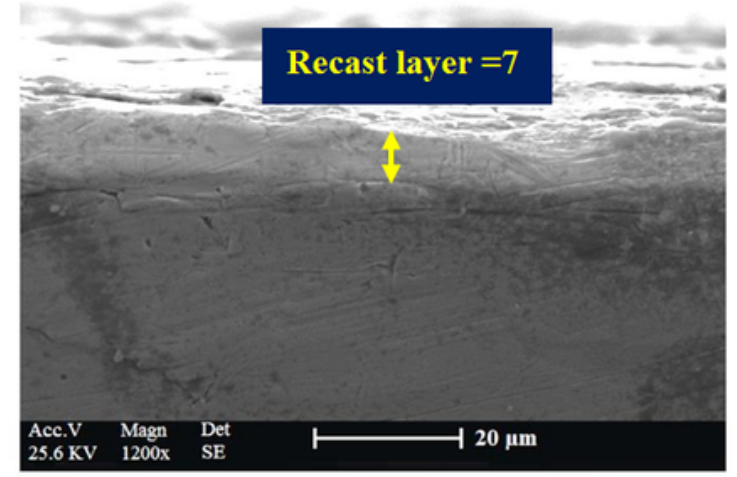

Deionized Water

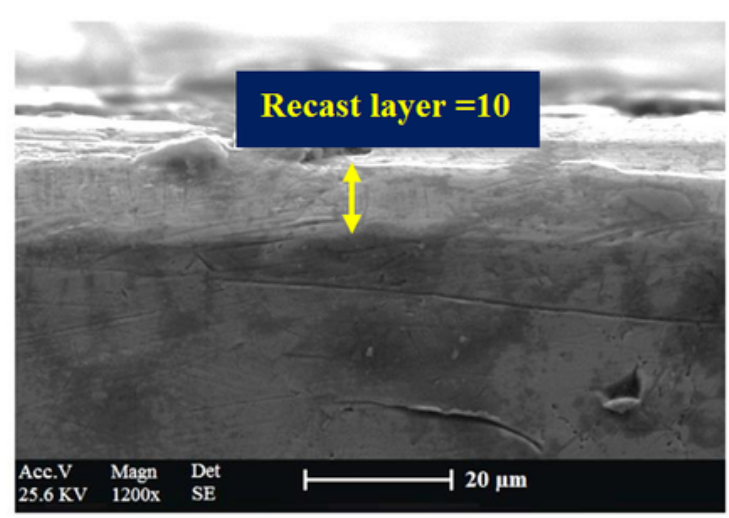

Kerosene

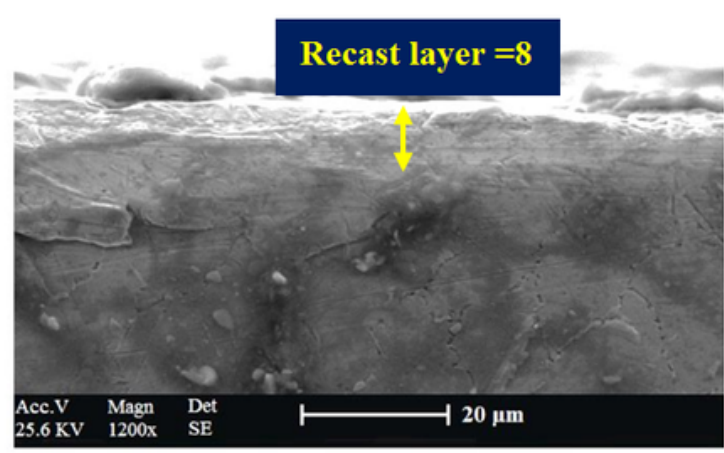

Kerosene

Figure 7

Cross-section profile of the recast layer in two types of dielectric fluid at the currents of 9 (a), 6 (b) and $3 \mathrm{~A}$ (c) 
(a). $I=9 \mathrm{~A}, \mathrm{~T}_{\text {on }}=150 \mu \mathrm{s}$

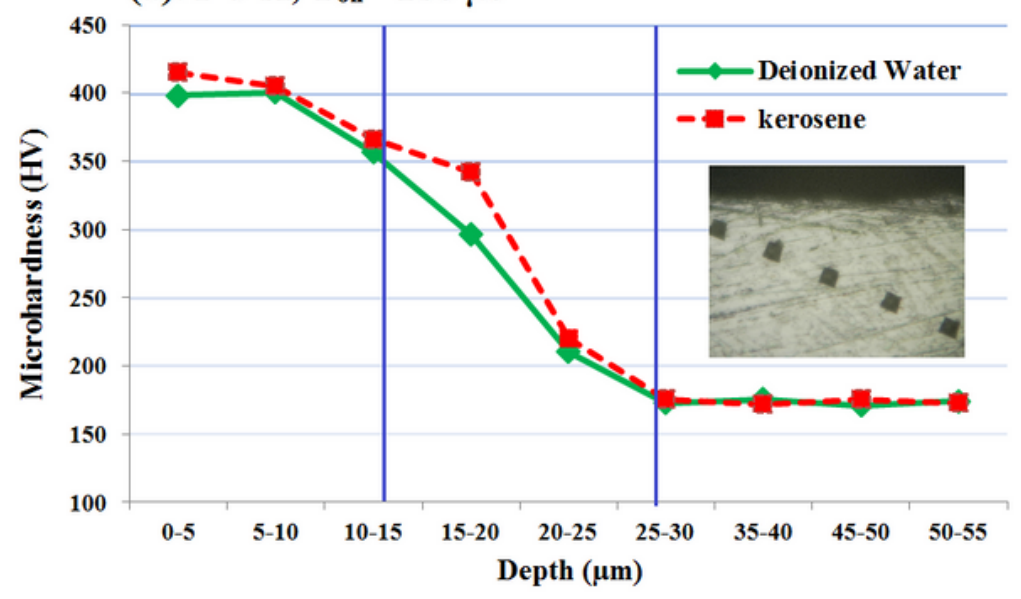

(b). $I=6 \mathrm{~A}, \mathrm{~T}_{\text {on }}=150 \mu \mathrm{s}$

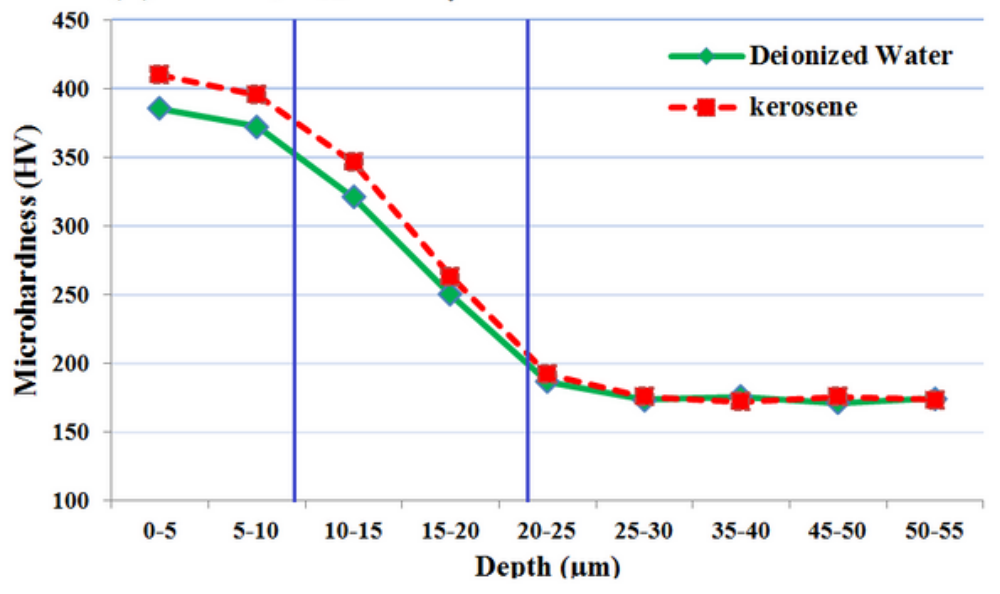

(c). I $=3 \mathrm{~A}, \mathrm{~T}_{\text {on }}=150 \mu \mathrm{s}$

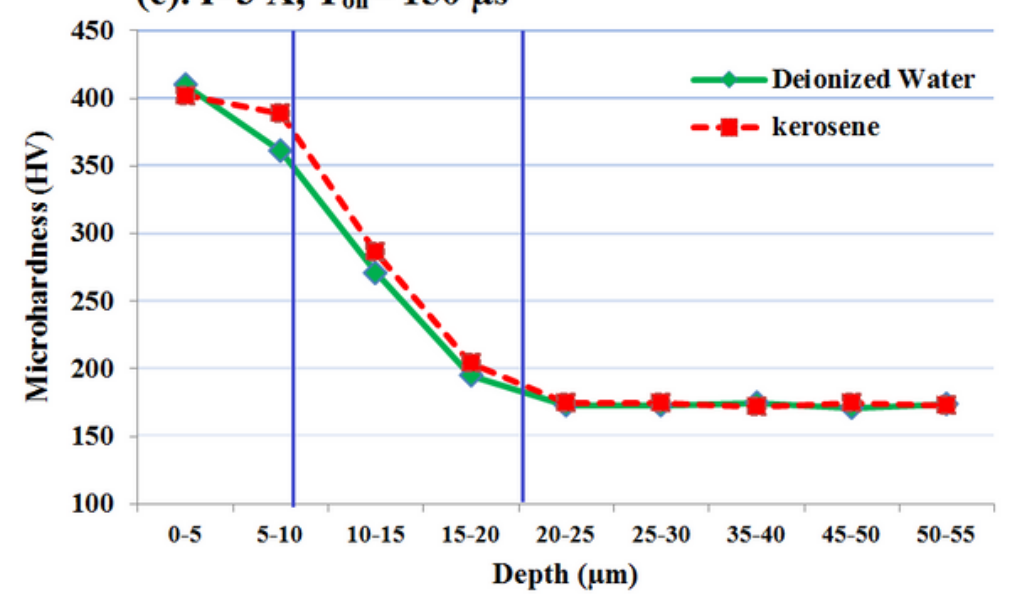

Figure 8

Microhardness profile of machined subsurface in two types of dielectric fluid at the currents of 9 (a), 6 (b) and $3 \mathrm{~A}(\mathrm{c})$ 